\title{
A matter of Motivation - The Effects of Risk Preference and Task Complexity on the Auditor's Motivation
}

\author{
Marco Haid ${ }^{\mathrm{a}, 1}$, Sabine Graschitz ${ }^{\mathrm{b}}$, Peter Heimerl ${ }^{\mathrm{c}}$ \\ ${ }^{a, c}$ Division for Management in Health and Sport Tourism, UMIT, Eduard-Wallnöfer-Zentrum 1, 6060 Hall in Tirol, Austria \\ ${ }^{b}$ Department of Accounting, Auditing, and Taxation, University of Innsbruck, Universitätsstraße 15, 6020 Innsbruck, Austria \\ (C) 2019 Marco Hais, Sabine Graschitz, Peter Heimerl. This is an open access article distributed under the \\ Creative Commons Attribution-NonCommercial-NoDerivs license (http://creativecommons.org/licenses/by- \\ $n c-n d / 3.0 /$
}

DOI 10.2478/WSBJBF-2019-0017

\begin{abstract}
This article examines whether and how several audit-specific attributes influence auditor's motivation. Following the literature, the research project focuses mainly on the impact of risk preference, task complexity and the liability situation in this issue. A 2x2 mixed-subjects case-based experiment was conducted to gain data for in-depth insights. In sum 209 master students with a major in accounting and auditing participated in the experiment. The results indicate that increased risk aversion leads to a higher observed task motivation. Regarding the task complexity, data analysis shows that increasing task complexity lowers auditor's motivation. This study contributes to the stream of judgment and decision making literature and offers new insights in to the relationship and dependence of inherent auditor-specific factors.
\end{abstract}

Keywords: motivation, risk attitude, task complexity, information quality, liability limitation

\section{Introduction}

The study contributes to the literature analysing the impact and relation of certain audit-specific factors. Specifically, the impact of individual risk preferences and task complexity on the auditor's motivation is analysed.

Prominent bankruptcies and accounting scandals (e.g. Enron, Worldcom, Parmalat) caused significant damage to several stakeholders and are examples that highlight the importance of reliable and high-quality financial information. Auditing is intended to ensure this reliability and high quality by acting as a control and verification unit between information preparers and information addressees. By fulfilling this purpose, auditing reduces the information asymmetry between the parties mentioned above and therefore contributes to increasing trust in the correctness and reliability of the financial data (Quick 2005). Ensuring the reliability of the financial information place high demands and requirements on the auditing. Especially, a valid and high-quality judgment and decision making are necessary to ensure high audit quality. Concerning the mentioned accounting scandals, it is becoming increasingly difficult to ignore the importance to understand and examine the factors, and its interactions that

\footnotetext{
${ }^{1}$ Corresponding author. Tel.: +0043-676-4645440

E-mail address: marco.haid@umit.at
} 
influence the judgment and decision making process and quality. A better understanding of these factors should provide an in-depth insight into the audit process and should contribute to its further development.

Mala and Chand (2015) followed the classification of Bonner (2008) regarding factors influencing judgment and decision making: (1) person variable, (2) task variable and (3) environmental variable. The auditor itself is one of the most significant influencing factors on the judgement and decision-making process and in addition to other person's inherent factors, especially the motivation of the auditor is critical for the judgement and decision making as it is the activation of an individual to recognise and solve a problem (Schwind 2011). Motivation is the psychological force that enables action and represents the individual's willingness to achieve objectives and therefore mainly influences the effort invested (Carver and Scheier 1998; Touré-Tillery and Fischbach 2014). The importance of motivation in the audit process is shown in many studies (e.g. Bonner 1994, 2008). It interacts as a moderator between the judgment performance and other audit-specific factors, for example task-specific such as task complexity (Nelson and Tan 2005; Mala and Chand 2015). In the past decades, many studies examined the impact of auditor's motivation on the judgment and decision-making process and/or the audit quality (e.g. McClelland 1961; Lawler 1994; Bonner 1994 and 2008; Bonner and Sprinkle 2002; Miller et al. 2006; MohdIskandar et al. 2012). So far, little research exists regarding the auditor's motivation and its influential factors in the context of an audit. Due to this research gap, this paper aims to examine different factors influencing the auditor's motivation and to contribute to a better understanding of this person-specific factor, and its drivers.

The literature provides five factors ${ }^{2}$ which mainly influence task motivation: (1) users perception of a task, (2) user's motivational orientation, (3) decision environment, (4) task characteristics and (5) task-user characteristics (Amabile 1988; Chan 2005; Chan and Song 2010). Several prominent and often discussed audit-specific factors can be related to this or are reflected in it.

Risk preference refers especially to (1) user's perception of a task, (2) user's motivational orientation and (3) decision environment. Audit research has shown an increased interest in the effects of the individual's risk preference on the audit quality (e.g. Johnstone 2000; Klersey and Roberts 2010; Pummerer et al. 2013; Laux et al. 2014) already for some time,. The auditor's risk preference has a considerable impact on the audit process as auditors follow mostly a risk-based approach and make their decisions based on risk assessments (Dusenbury et al. 2000; Johnstone 2000). According to Klein and Scholl (2014) risk preference determines risk behaviour and in contrast to risk-loving individuals, risk-averse individuals are more eager to avoid risk instead of looking for opportunities. Similarly, Atkinson (1957) argues that motivation can be determined by the motive to achieve success and/or the motive to avoid failure and it depends on the preference of the individual which motive has a stronger impact on the overall motivation. Given all these insights, it can be argued that the auditor's risk preference might influence its motivation. To examine this relationship, this paper seeks to answer the following question:

\section{RQ1: How does the auditor's risk preference affect the auditor's motivation?}

Task complexity can be mainly attributed to (4) task characteristics and (5) task-user characteristics regarding the influence on motivation. A stream of literature examined the impact of task complexity on the audit process and showed negative effects on the auditor's judgment performance (Bonner 1994, 2008; Mala and Chand 2015). Task complexity among others influences individuals regarding complexity-adequate resource allocations (e.g. Prawitt 1995) or in terms of using support systems (Chan et al. 2014). According to Chan (2005) the effect of complexity on motivation is dependent on a person's motivational orientation. Regarding these insights, task complexity has an impact on the behaviour of individuals and might further affect motivation. For the investigation concerning this matter the following research question occurs:

\section{RQ2: How does task complexity affect the auditor's motivation?}

The examined factors in this study are in particular relevant to the influence and measurement of motivation (e.g. Chan 2005; Chan and Song 2010, Touré-Tillery and Fischbach 2014). As motivation is an important factor within audit tasks (e.g. Bonner 1994, 2008), the examined factors are essential and critical for the whole audit process. Thus, they were examined in this study which tends to offer further insights on influencing factors of the auditor's motivation. A deeper understanding of the relationship and impacts of and on motivation should lead to a more detailed view of critical factors within the audit process. Practitioners should benefit from the study in terms of understanding and increasing the motivation of auditors. Furthermore, the insights should support leading audit teams as well as assigning tasks and the allocation of resources.

The remainder of the present study is structured as follows: In section 2 the literature review and hypotheses development can be found. Section 3 includes the research design, section 4 the data analyses and section 5 the discussion of results. Section 6 contains the conclusions, limitations and implications.

\footnotetext{
${ }^{2}$ The following sections refer to the factors using the numbers in brackets next to the factor.
} 


\section{Literature Review and Development of Hypothesis}

\subsection{Motivation}

While knowledge, experience and expertise can be seen as the ability to fulfil a task, motivation represents the willingness to solve and handle it (Gronewold 2006; Rheinberg 2010). According to Atkinson (1957) motivation occurs due to the willingness to achieve success or to avoid failure. The theory of McClelland (1961) indicates that motivation results from three dominant needs: achievement, power and affiliation. The study of Touré-Tillery and Fishbach (2014) determines motivation as the 'psychological force that enables action'. Task motivation arises from the willingness to engage in certain activities of interest (Ryan and Deci 2000; Chan and Song 2010) and entails positively valued experience deduced from the task itself (Thomasand Velthouse (1990). The literature distinguishes between intrinsic and extrinsic motivation (Jost 2000; Rheinberg 2010; Schwind 2011). While intrinsic motivation occurs due to internal desires to do something for its own sake, extrinsic motivation arises because of external factors such as reward or punishment (Kanfer 1990; Rheinberg 2010)

Task motivation is a critical factor for high-quality performances (Utman 1997), and its influence on task and work performance has been investigated in a variety of studies (e.g. Hackman and Oldham 1980; Lawler 1973; Tomas and Velthouse 1990). Regarding the judgment and decision making in auditing, it is shown that a higher motivation leads to an increasing effort of the individual and therefore to a higher judgment performance, a better judgment and decision making process as well as to a higher audit quality (e.g. Bonner 1994, 2008; Bonner and Sprinkle 2002; Mohd-Sanusi and Mohd-Iskandar 2007; Bonner 2008). The influence of workmates' feedback on motivation is examined in the study of Miller et al. (2006). The results show a positive effect of such discussion on the motivation and further on the overall performance. Mohd-Sanusi and Mohd-Iskandar (2007) also investigated the influence of feedback and expanded the examination by monetary remuneration and control. According to the study of Miller et al. (2006), the results indicate a positive influence of feedback, monetary remuneration and control on the motivation and the performance. The impact of accountability is investigated by Tan and Kao (1990); with an experiment, it is shown that accountability positively influences the motivation and the invested effort. Similar results can be found in the study by Mohd-Iskandar et al. (2012) which examined the effect of pressure caused by accountability on the invested effort and performance. The results also show a positive influence of pressure on the performance due to increased motivation. Increasing pressure leads to higher invested effort and encourages caution and responsibility (DeZoort et al. 2006).

Besides the positive effects of motivation, also irrelevant and adverse effects are also discussed in the literature. Bonner $(1994,2008)$ shows that motivation is irrelevant when the task is too easy or too difficult. Also, the negative effects of motivation on the performance may occur, especially when the optimal motivational stimulation is exceeded (e.g. Humphreys and Revelle 1984; Eysenck 1986; Ashton 1990)

Thus, the auditor's motivation is an essential component of the audit process and plays a vital role regarding audit quality. According to these insights, motivation is a critical factor for the audit process as it represents the individual willingness to achieve objectives and therefore mainly influences the effort invested.

\subsection{Risk preference}

According to Sitkin and Weingart (1995) the risk preference has an impact on the risk perception and determines the risk behaviour. Risk preferences can be classified as risk-averse, risk-neutral and risk-loving (Laux et al. 2014). According to Klein and Scholl (2014) risk-averse individuals are more anxious to avoid risk than to look for opportunities. In contrast, risk-loving individuals are less interested in avoiding risk and tend to prefer the possibility of an opportunity. Risk perception is mainly affected by the controllability of a task (Sandman 1987), the extensity of risk and the confidence of the individual (Pablo et al. 1996).

Farmer (1993) was one of the first who examined risk preference in an audit context and found that senior auditors and managers tend to be risk-averse. Nevertheless, the results showed no differences between the preference groups. Another stream of literature dealing with risk perception in auditing, investigated the client retention decisions in this context. According to the majority of the results, risk-loving auditors tend to accept higher risk clients and charge higher risk premiums (e.g. Klersey and Roberts 2010; Amir et al. 2014). A number of studies have examined gender differences regarding risk preferences. Hardies et al. (2013) found that females tend to be more risk-averse than males. In contrast, Lehtinen and Kvist (2018) showed that gender has no impact on risk preference. Several studies have been carried out on the impact of risk and risk perception on audit quality (e.g. Pummerer et al. 2013; Amir et al. 2014; DeFond and Zhang 2014). According to the majority of the findings, risk preference has an important impact on the decisions of an auditor like wealth, effort or audit fee as well as on the audit quality. Nevertheless, no reliable evidence exists regarding the impact of risk preference on auditor's motivation.

According to Atkinson (1957), motivation is determined by the willingness to achieve success or to avoid failure. In an audit context, we assume that the avoidance of failure is the primary driver for motivation because only failure (i.e. inappropriate audit opinion) will cause significant consequences in the end. Risk-averse individuals are more anxious regarding risk and therefore more eager to avoid them. That means in addition to the 
motivation to achieve success, the overall motivation of a risk-averse individual is additionally reinforced by the motivation to avoid failure. Based on these insights we assume that individuals with a higher risk aversion are more motivated due to a higher willingness to avoid negative consequences. Therefore, the following hypothesis is developed:

H1: Increasing risk aversion leads to higher motivation.

\subsection{Task Complexity}

Campbell (1988) divided complexity into a subjective and an objective dimension. Gill and Hicks (2006) extended this classification and categorised complexity as (a) a subjective psychological experience, (b) an interaction between task-specific and person-specific characteristics and (c) a function of objective task characteristics. According to Kahnemann (1973), complexity can be defined as the amount of capacity or mental processing which is required to fulfil a task. It increases with a higher number of similarities, higher number of alternatives or the number of necessary procedures (Bonner 1994; Stone and Kadous 1997; Chun 2005). Task complexity can occur at the stages of information input, information processing, or the output of a task (Bonner 1994; Chun 2005).

Task complexity belongs to the task-specific factors influencing the audit procedure, and therefore judgment and decision-making (Nelson and Tan 2005; Bonner 2008, Mala and Chand 2015). Bonner (1994) discussed an adverse effect of task complexity and a positive effect of skill and motivation on the judgment performance. Several further factors influencing the judgment performance are examined in the light of task complexity such as goal orientation (Mohd-Sanusi and Mohd-Iskandar 2007), performance incentives (Mohd-Sanusi et al. 2007) or self-efficacy (Mohd-Iskandar et al. 2012). These studies show that the primarly positive influence of the investigated factors on judgment performance decreases or disappears under high task complexity. Bowrin (2010) examined the relationship between time pressure, audit effectiveness and complexity and showed a negative interactional relationship in this context. The studies of Chung/Monroe (2001) and O'Donnell/Johnson (2001) investigate the interaction of gender, task complexity and judgment performance. The results show an interaction effect of gender and task complexity and significant differences between females and males regarding this issue. To sum up, research has shown several and essential impacts of task complexity on the audit process. However, there has been little discussion on its influence on motivation.

According to the theory of Atkinson (1957), task complexity could affect motivation in different ways: regarding success, the incentive effect will be stronger under high complexity due to the pride of the individual to fulfil the task successfully; regarding failure the motivation increases when the complexity is low because the shame is higher than in the case of more difficult tasks. According to the motivational framework, Chan (2005) and the study of Chun and Song (2010), task motivation is expected to be higher when the task is less complex. Thus, taking all insights together, individuals may become more motivated when they perceive the task to be low in difficulty.

Summarising, the willingness to achieve success as well as the willingness to avoid failure influence motivation. In an audit situation, however, it is assumed that especially the avoidance of losses, financial or nonfinancial, is the primary driver of auditor's motivation and with increasing complexity, it is getting more challenging to avoid failure. Based on this assumption and insights of the literature, it is assumed that motivation decreases with increasing complexity. Thus, the following hypothesis is developed:

H2: Increasing complexity leads to lower motivation.

\section{Research Design}

\section{$3.1 \quad$ Research Method}

The measurement of risk preference and the individual's motivation is necessary to empirical investigate the interaction and the influence factors of these variables. Therefore, to conduct the research project a case based experimental research design (the experiment is provided in the appendix) was chosen. The experimental design allows to measure the individual's risk perception as well as the task complexity and enables to measure and investigate the individual's motivation in a controlled environment. Another advantage is the higher construct validity which arises due to the direct measurement of the variables instead of using archival data.

Case-based experiments have a long tradition in audit research (e.g. Farmer 1993; Stone/Kadous 1997; Bonner 2008; Fatemi 2012; Koch and Schunk 2013) throughout a variety of topics (e.g. judgment and decision-making). Thus far, however, no experimental setting was used yet in this particular setting.

The experiment is divided into four steps. In the first step, the measurement of the individual risk preference is conducted. In the second step, the participants are provided with the case study including information about a fictitious company, especially its financial statement. The participants were asked to determine and allocate the necessary resources to conduct an audit. One group received low complexity information, and the other group was confronted with higher complexity. Based on the task and the manipulated case study, the individual's motivation is measured in the third step. The last step contains the manipulation checks and the collection of demographical data. 


\subsection{Research Design and Administration}

The experiment is designed as a $2 \times 2$ mixed subjects experiment. The task complexity is manipulated between subjects. Besides these two manipulation variables the influence of the individual risk preference on the auditor's motivation is examined. Hence, the independent variables in this study are the risk preference, the task complexity as well as the liability situation and the dependent variable is the individual's motivation. The data collection period and several questions regarding the delivered information of the fictitious company are installed to serve as control variables. The between-subjects manipulation of the task complexity offers the possibility to investigate the reaction of two separated populations towards motivation. Specifically, it is an advantage as it enables to conduct an in-depth and isolated examination of the risk preference in both complexity states.

The experimental design had been tested twice with students and practitioners before its finalisation. The data collection was conducted using paper- and computer- in the facilities of the university in a laboratory setting.

\subsection{Experimental Task and Variables}

The experiment contains the manipulation variable task complexity. Several constructs and approaches for its definition and measurement exist which are discussed in section 2.3. In this respect, it can be defined as the set of necessary capacities of cognitive processes for the task performance (Kahneman 1973). Furthermore, it can be seen as the number of specifications and steps to reach a specific goal. For the manipulation objective, complexity attributes were used which among others include the degree of uncertainty caused by lack of structure (Funke 1991; Gill and Hicks 2006), the number of alternative paths that are possible using different performance strategies (Jacko and Salvendy 1996; Gill and Hicks 2006), the number of task attributes (e.g. required number of criteria) and alternatives (e.g. number of alternatives, discriminability) (Fisher et al. 2003; Klemz and Gruca 2003; Gill and Hicks 2006) or the amount of information (Bonner 1994).

At the beginning of the experiment, the risk preference of the participants is measured with standardised questions on a seven-point Likert scale regarding the individual's risk behaviour and attitude in different financial and non-financial situations. This measurement method can be classified as subjective psychological processes to measure an individual's risk attitude (Zuber and Guthier 2003). Furthermore, the participants conducted a Holt and Laury (2002) lottery which was used to control the question-based risk attitude measurement. Within the lottery, the participants choose between pairs of payouts which differ in the amount and probability of their occurrence. This combination of methods to measure risk preference has been chosen because individual's risk preference may not be stable over all domains (Weber et al. 2002) and no predominant and distinct measurement of risk preference exists. Moreover, it is possible to gain a more accurate and selective measurement of risk attitude in a specific domain or a particular situation, which should lead to more valid and reliable results and it also allows to cover a broad range of aspects regarding risk preference. Based on the result of the measurements, the participants were divided into three risk groups, namely risk-averse, risk-neutral and risk-loving.

There are a variety of methods and approaches for measuring individual's motivation which can be classified as a) cognitive and effective measures and b) as behavioural measures within two dimensions of motivation, namely outcome-focused and process-focused (Touré et al. 2014). While behavioural measures of motivation refer to more objective identifiable indicators like speed or performance, the cognitive and effective measures of motivation include most of all the activation, evaluation, perception or experience of goal-related constructs as well as the subjective experience they evoke (Touré-Tillery and Fishbach 2014). For the present study, the cognitive and effective measure dimension is chosen due to characteristics of the case study and the possibility to gain deeper insights and further information regarding the individual's motivation for the task. In this context, motivation is mainly measured as the degree to which a relevant task-related object is evaluated positively, as individual's degree of interest or enjoyment, as perceived competence, or as felt pressure and tension while performing a given activity (Ryan et al. 1991; Touré-Tillery and Fishbach 2014). Concerning the work of Eccles and Wigfield (2002) an individual's value of a task strongly depends on the individual's needs and goals. The value aspects of motivation include the goals for the task as well as beliefs about its interest, importance or utility (Pintrich and de Groot 1990) and influence the intensity of behaviour within a task (Chan et al 2014; Pintrich and Schrauben 1992). In contrast to the utility which is seen as an extrinsic attribute, interest and importance are considered as intrinsic features (Eccles and Wigfield 1995, 2002; Chan et al. 2014). Interest results in enhanced motivation and refers to a particular situation or to certain individual feelings or stimulations (Schiefele 1999; Hidi and Harackiewicz 2001). Importance also influences the intrinsic motivation and can be referred to as the value individual places on performing well in an activity (Eccles et al. 1983). Based on these insights, the measurement of interest and importance values is chosen for the present study because these factors are the primary driver for individual's motivation to perform a task primarily for the sake of the task itself(Wigfield and Eccles 1992; Eccles and Wigfield 1995, 2002; Chan et al. 2014). Based on the interest and importance dimensions, standardised questions were developed to measure the individual's motivation on a seven-point Likert scale. This measurement approach has already been used in prior audit research (e.g. Chan et al. 2014). 


\subsection{Participants}

Following prior work in the field, business administration students with a major in auditing at the master and $\mathrm{PhD}$ level were taken as participants for the experiment as proxies for auditors (Frederickson and Miller 2004; Elliott et al. 2007; Fatemi 2012; Zimmermann 2016) because this study aims to investigate influences on motivation which means that there is not much experience required to be involved in the experiment as the focus lies more on an individual's state of feelings than as on conducting actual audit-specific tasks or decisions.

Ninety-nine $(47.10 \%)$ participants were female, $105(50.00 \%)$ were male, and five $(2.90 \%)$ did not give any information regarding their gender. The average age of the participants was 23.33 years. Tables 1 and 2 summarise the demographics regarding gender and age.

\begin{tabular}{llcccc}
\multicolumn{6}{l}{ Table 1. Demographics: gender. } \\
\hline Valid & Frequency & Percent & Valid Percent & Cumulative Percent \\
& Female & 99 & 47.4 & 48.5 & 48.5 \\
& Male & 105 & 50.2 & 51.5 & 100.0 \\
Missing & Total & 204 & 97.6 & 100.0 & \\
Total & System & 5 & 2.4 & & \\
\hline
\end{tabular}

\begin{tabular}{|c|c|c|c|c|c|}
\hline & $\mathrm{N}$ & Minimum & Maximum & Mean & Std. Deviation \\
\hline Age & 204 & 18.00 & 32.00 & 23.2843 & 2.40229 \\
\hline Valid N (listwise) & 204 & & & & \\
\hline
\end{tabular}

About $40 \%$ of the participants were working in the accounting, auditing or common similar areas. Another 20 $\%$ have already been engaged in these fields. On average, the experiment lasted $20 \mathrm{~min}$, and every participant was awarded an average payment of 12 EUR.

\subsection{Data Screening and Manipulation Checks}

In sum, 211 students participated in the experiment. Two datasets had to be removed due to incomplete responses pertaining to the risk preference and motivation measurements. In sum 209 valid datasets could be collected. Manipulation checks were conducted to ensure that the participants correctly perceived the case study and that the manipulation was recognised. Therefore the participants were asked to answer questions regarding the complexity of the case. Table 3 shows the results of the Kruskal Wallis test which indicates significant differences within three out of four questions between the manipulation groups. Hence, it can be assumed that the participants react to the complexity manipulation.

Table 3. Manipulation Check.

\begin{tabular}{|c|c|c|c|}
\hline & 1-high complexity, 2-low complexity & $\mathrm{N}$ & Mean Rank \\
\hline \multirow[t]{3}{*}{ mc_1 } & 1.00 & 95 & 136.99 \\
\hline & 2.00 & 109 & 72.44 \\
\hline & Total & 204 & \\
\hline \multirow[t]{3}{*}{$\overline{\text { mc_2 }}$} & 1.00 & 95 & 140.68 \\
\hline & 2.00 & 109 & 69.22 \\
\hline & Total & 204 & \\
\hline \multirow[t]{3}{*}{ mc_3 } & 1.00 & 94 & 93.77 \\
\hline & 2.00 & 109 & 109.10 \\
\hline & Total & 203 & \\
\hline \multirow[t]{3}{*}{ mc_4 } & 1.00 & 95 & 118.25 \\
\hline & 2.00 & 109 & 88.77 \\
\hline & Total & 204 & \\
\hline \multicolumn{4}{|c|}{ Test Statistics ${ }^{\mathrm{a}, \mathrm{b}}$} \\
\hline & mc_2 & mc 3 & mc 44 \\
\hline Chi-Square & 62,385 & 3,664 & 13,062 \\
\hline Df & 1 & 1 & 1 \\
\hline Asymp. Sig. & ,000 &, 056 & ,000 \\
\hline
\end{tabular}

Further questions regarding the liability situation were installed to ensure that the potential loss is apparent to all participants. No one failed the manipulation checks, and thereby 209 datasets were gathered. 


\section{Data Analysis}

Within the data analysis, the responses of the participants to significant differences were examined. Due to the characteristics of the data, the non-parametric tests Mann-Whitney U, Kruskal-Wallis and Wilcoxon Signed-Rank test were used (Hollander and Wolfe 1999). Furthermore, the Jonckheere-Terpstra test was used to analyse significant trends.

\subsection{Risk Preference}

Based on the responses to the questions and measurements regarding risk preferences, the participants were classified into three groups risk-averse, risk-neutral and risk-loving. Table 4 shows the number of participants in each group:

\begin{tabular}{ll} 
Table 4. Risk groups. \\
\hline Group & N \\
\hline Risk-averse & 27 \\
Risk-neutral & 137 \\
Risk-loving & 45 \\
Sum & 209 \\
\hline
\end{tabular}

The responses to the standardised questions of the motivation measurement were combined and summarised to a single variable for the analysis. The procedure avoids the problem of outliers within single questions and allows a weighted and valid evaluation regarding the individual's motivation. To examine differences of this variable between the risk groups a Kruskal-Wallis test was conducted. Table 5 displays the mean ranks as well as the result of the test.

Table 5. Kruskal-Wallis test risk preferences.

\begin{tabular}{|c|c|c|c|}
\hline & $\begin{array}{c}\text { 1-risk averse, 2-risk neutral, } \\
\text { 3-risk loving }\end{array}$ & $\mathrm{N}$ & Mean Rank \\
\hline 1-high motivation to & 1,00 & 27 & 81.00 \\
\hline \multirow[t]{3}{*}{ 7-low motivation } & 2,00 & 137 & 105.79 \\
\hline & 3,00 & 45 & 116.99 \\
\hline & Total & 209 & \\
\hline
\end{tabular}

Test Statistics ${ }^{\mathrm{a}, \mathrm{b}}$

\begin{tabular}{lc}
\hline \multicolumn{2}{c}{ Test Statistics $^{\mathrm{a}, \mathrm{b}}$} \\
\hline Chi-Square & 6.160 \\
Df & 2 \\
Asymp. Sig. & .046 \\
\hline \multicolumn{2}{c}{ a. Kruskal Wallis Test } \\
b. Grouping Variable: 1 1-risk averse,
\end{tabular}

The risk-averse group shows the highest motivation with a mean rank of 81.00 followed by the risk-neutral group (mean rank $=105.79$ ). The lowest motivation is examined within the risk-loving group (a smaller number indicates a higher motivation) with a mean rank of 116.99. According to the analysis, the differences between the groups are significant (P: 0.046) with a Cohen's effect size value of $\mathrm{d}=0.287$.

Further, a Jonckheere-Terpstra test was conducted. The results show a significant underlying trend at a p-value of 0.019. Table 6 summarises the test.

Table 6. Jonckheere-Terpstra test risk preferences

\begin{tabular}{lc}
\hline & 1-high motivation to 7-low motivation \\
\hline Number of Levels in 1-risk averse, 2-risk neutral, 3-risk loving & 3 \\
$\mathrm{~N}$ & 209 \\
Observed J-T Statistic & 6522.500 \\
Mean J-T Statistic & 5539.500 \\
Std. Deviation of J-T Statistic & 420.242 \\
Std. J-T Statistic & 2.339 \\
Asymp. Sig. (2-tailed) & .019 \\
\hline
\end{tabular}

Figure 1 illustrates both, the results of the Kruskal-Wallis test as well as the Jonckheere-Terpstra test. The graphs depict the trend-shaped progression and show once again that motivation increases as risk aversion increases. 


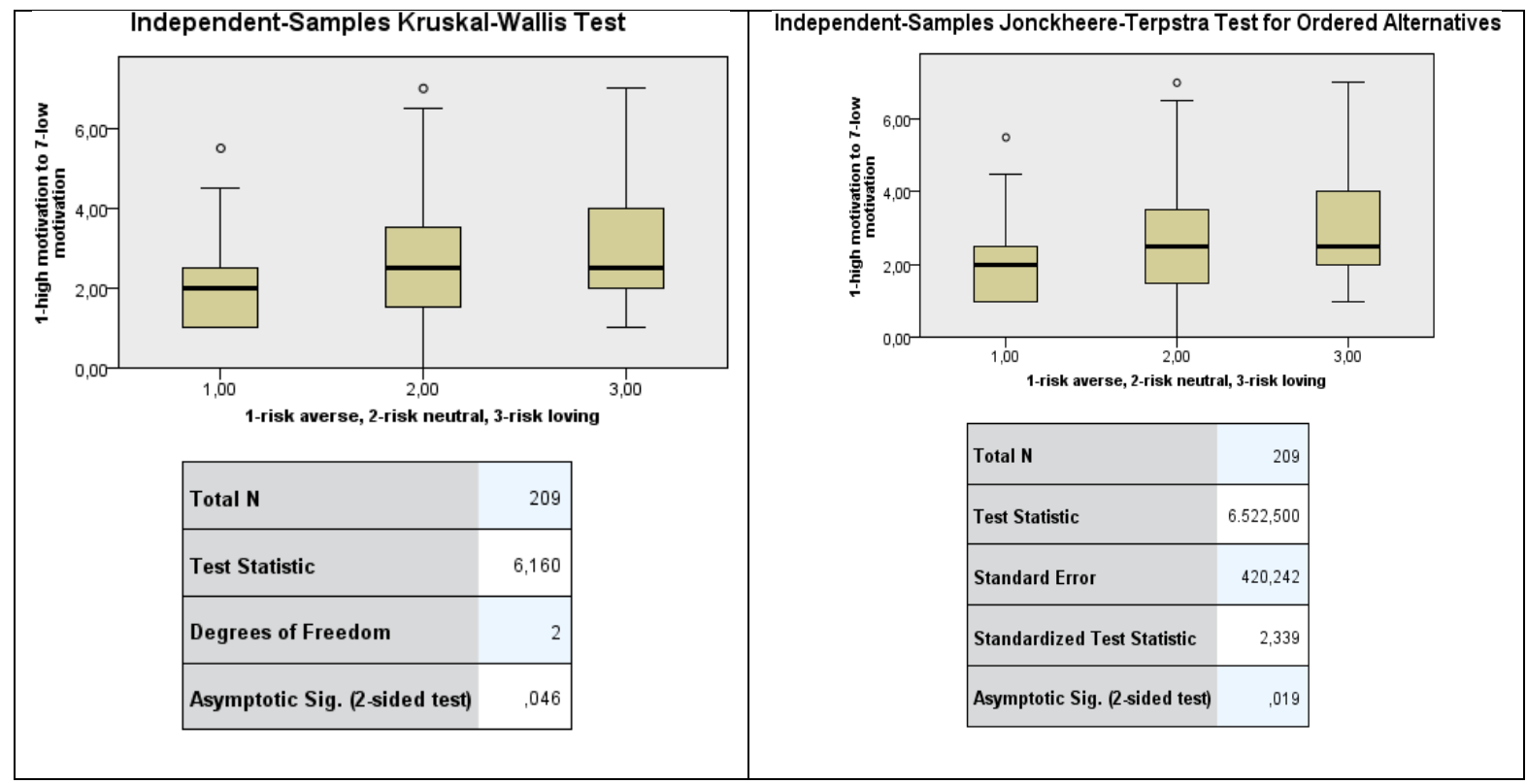

Fig. 1. Illustration of Kruskal-Wallis test and Jonckheere-Terpstra test risk preferences

To summarise, the analysis shows a significant impact of risk preference on the auditor's motivation. Thereby, risk-averse individuals showed the highest, risk-neutral individuals the second highest and risk-loving individuals the lowest motivation. Hence H1, according to which increasing risk aversion leads to higher motivation, can be supported.

To further evaluate the influence of risk preference, the complexity was involved and combined into six groups: risk averse and low complexity, risk averse and high complexity, risk neutral and low complexity, risk neutral and high complexity, risk loving and low complexity as well as risk loving and high complexity. This additional analysis and the combination of the variables offers two advantages: first, as task complexity is manipulated between subjects this is an efficient method to involve both manipulation groups to oppose the responses and second, it offers the possibility to investigate the reaction of each risk preference group on changes in complexity, and thus a first validity check is possible. Furthermore, an in-depth examination of underlying trends is supported.

The Kruskal-Wallis test was used to examine the data regarding differences in the mean rank between the six groups. Table 7 displays the mean ranks as well as the test statistics. In line with the previous results, the analysis shows significant differences between the groups (P: 0.033) with a Cohen's effect size value of $d=0.382$. The riskaverse groups ( 1 and 2 ) shows the highest motivation (a smaller number indicates a higher motivation) following the risk-neutral groups (3 and 4). The lowest motivation was examined within the risk-loving groups (5 and 6). Furthermore, the results show that every risk group reacts similarly to changes in complexity and with increasing complexity the motivation decreases.

Table 7. Kruskal-Wallis risk/complexity combination

\begin{tabular}{llcc}
\hline & $\mathrm{N}$ & Mean Rank \\
\hline 1-high motivation to 7-low motivation & 1: risk averse + low complexity & 17 & 72.18 \\
& 2: risk averse + high complexity & 10 & 96.00 \\
& 3: risk neutral + low complexity & 72 & 99.95 \\
& 4: risk neutral + high complexity & 65 & 112.26 \\
& 5: risk loving + low complexity & 23 & 100.50 \\
& 6: risk loving + high complexity & 22 & 134.23 \\
& Total & 209 & \\
\hline
\end{tabular}

Test Statistics ${ }^{\mathrm{a}, \mathrm{b}}$

\begin{tabular}{lc}
\hline & 1-high motivation to 7-low motivation \\
\hline Chi-Square & 12.108 \\
Df & 5 \\
Asymp. Sig. & .033 \\
\hline
\end{tabular}

a. Kruskal Wallis Test

b. Grouping Variable: 1-risk averse + low complexity, 2-risk averse + high complexity, 3-risk neutral + low complexity, 4-risk neutral + high complexity, 5-risk loving + low complexity, 6-risk loving + high complexity 
In a further step, it was examined whether the differences follow a significant trend. Regarding the results of the Jonckheere-Terpstra test, it can be indicated that there is an underlying trend between the six groups (P: 0.005). Table 8 summarises the results:

Table 8. Jonckheere-Terpstra test risk/complexity combination.

\begin{tabular}{lc}
\hline Number of Levels in 1-risk averse + low complexity, 2-risk averse + high & 6 \\
complexity, 3-risk neutral + low complexity, 4-risk neutral + high complexity, & 209 \\
5-risk loving + low complexity, 6-risk loving + high complexity & 958.000 \\
$\mathrm{~N}$ & 8217.500 \\
Observed J-T Statistic & 481.298 \\
Mean J-T Statistic & 2.837 \\
Std. Deviation of J-T Statistic & .005 \\
Std. J-T Statistic & .005 \\
Asymp. Sig. (2-tailed) &
\end{tabular}

Fig. 2 provides the illustration of the findings.

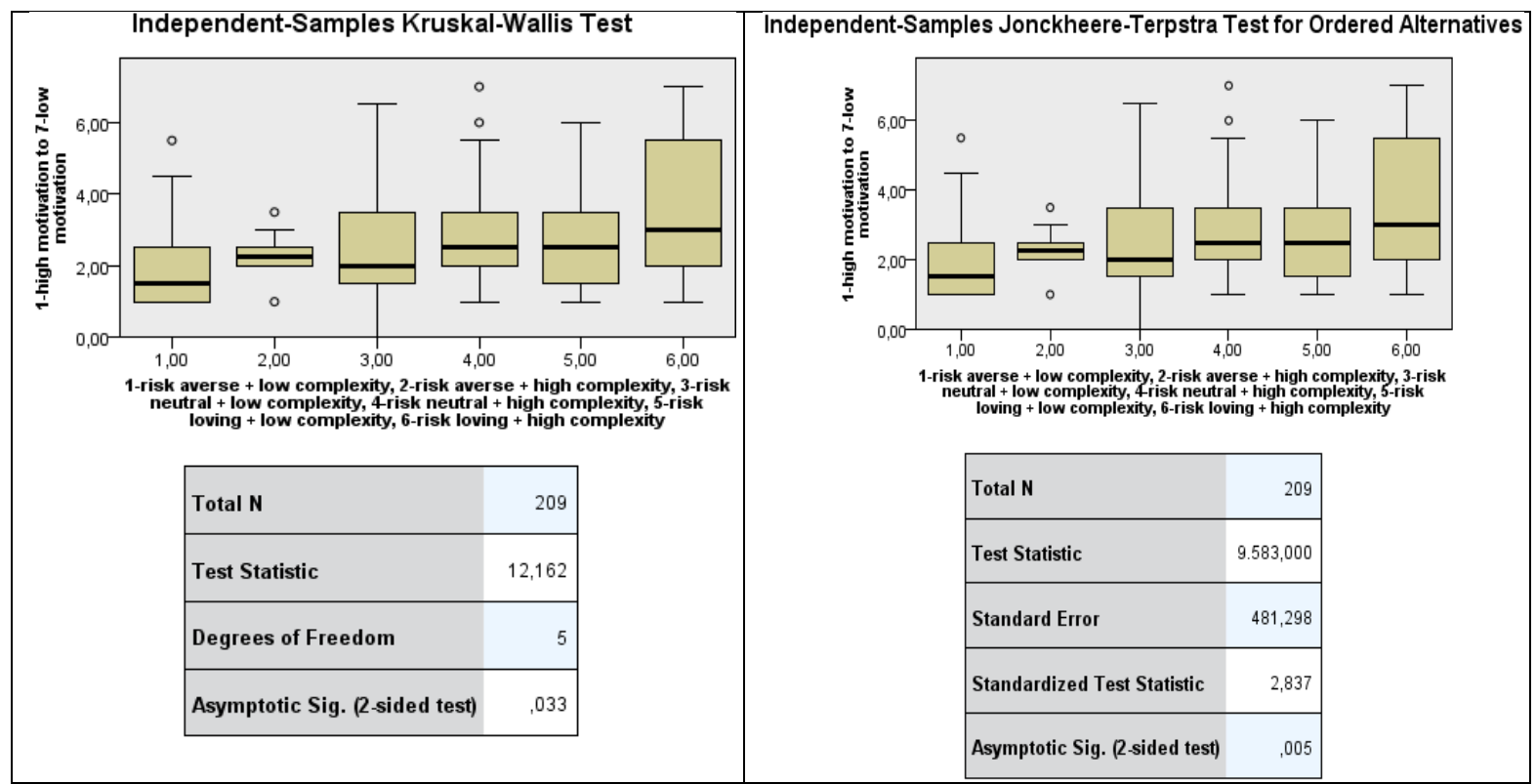

Fig. 2. Kruskal-Wallis Test and Jonckheere-Terpstra test for the risk attitude/complexity combination

Within the figure the underlying trend gets visible, and one can see that increased risk aversion leads to higher motivation. Moreover, when looking at the risk pairs, it is shown that every type of risk preference reacts with increasing task complexity to decreasing motivation. Further investigations regarding task complexity are carried out under section 4.2 .

Therefore, the results indicate once again that risk preference has an important impact on the auditor's motivation, and additionally support $\mathrm{H} 1$.

\subsection{Task Complexity}

In addition to the insights in section 4.1 regarding the influence of task complexity on auditor's motivation, further analyses are performed in this section. The task complexity has been manipulated between subjects. For the analysis a Mann-Whitney $U$ test is conducted to examine differences between the high-complexity sample and the low-complexity sample.

The results of the analysis are presented below. The mean rank of the high-complexity group is 115.57 whereas the low-complexity population has a mean rank of 95.85. The dataset was analysed using a Mann-Whitney U Test leading to the results that the difference are significant $(U=4407.00, p=0.018)$. Further, Cohen's effect size value $(\mathrm{d}=0.33)$ suggests a small to moderate, practical significance.

Table 9. Mann-Whitney U test task complexity.

\begin{tabular}{lccc}
\hline & 1-high complexity, 2-low complexity & $\mathrm{N}$ & Mean Rank \\
\hline 1-high motivation to 7-low motivation & 1.00 & 97 & 115.57 \\
& 2.00 & 112 & 95.85 \\
& Total & 209 & \\
\hline
\end{tabular}


Test Statistics ${ }^{\mathrm{a}}$

\begin{tabular}{lc}
\hline & 1-high motivation to 7-low motivation \\
\hline Mann-Whitney U & 4407.000 \\
Wilcoxon W & 10735.000 \\
$Z$ & -2.373 \\
Asymp. Sig. (2-tailed) & .018 \\
\hline \multicolumn{2}{c}{ a. Grouping Variable: 1-high complexity, 2-low complexity }
\end{tabular}

Furthermore, a Jonckheere Terpstra test indicates a significant trend-based difference between the two complexity populations $(\mathrm{P}=0.018)$ (Table 10$)$.

Table 10. Jonckheere-Terpstra test task complexity.

\begin{tabular}{lc}
\hline & 1-high motivation to 7-low motivation \\
\hline Number of Levels in 1-high complexity, 2-low complexity & 2 \\
$\mathrm{~N}$ & 209 \\
Observed J-T Statistic & 4407.000 \\
Mean J-T Statistic & 5432.000 \\
Std. Deviation of J-T Statistic & 431.905 \\
Std. J-T Statistic & -2.373 \\
Asymp. Sig. (2-tailed) & .018 \\
\hline
\end{tabular}

Fig. 3 illustrates the results of the Mann-Whitey U test as well as the Jonckheere-Terpstra test.

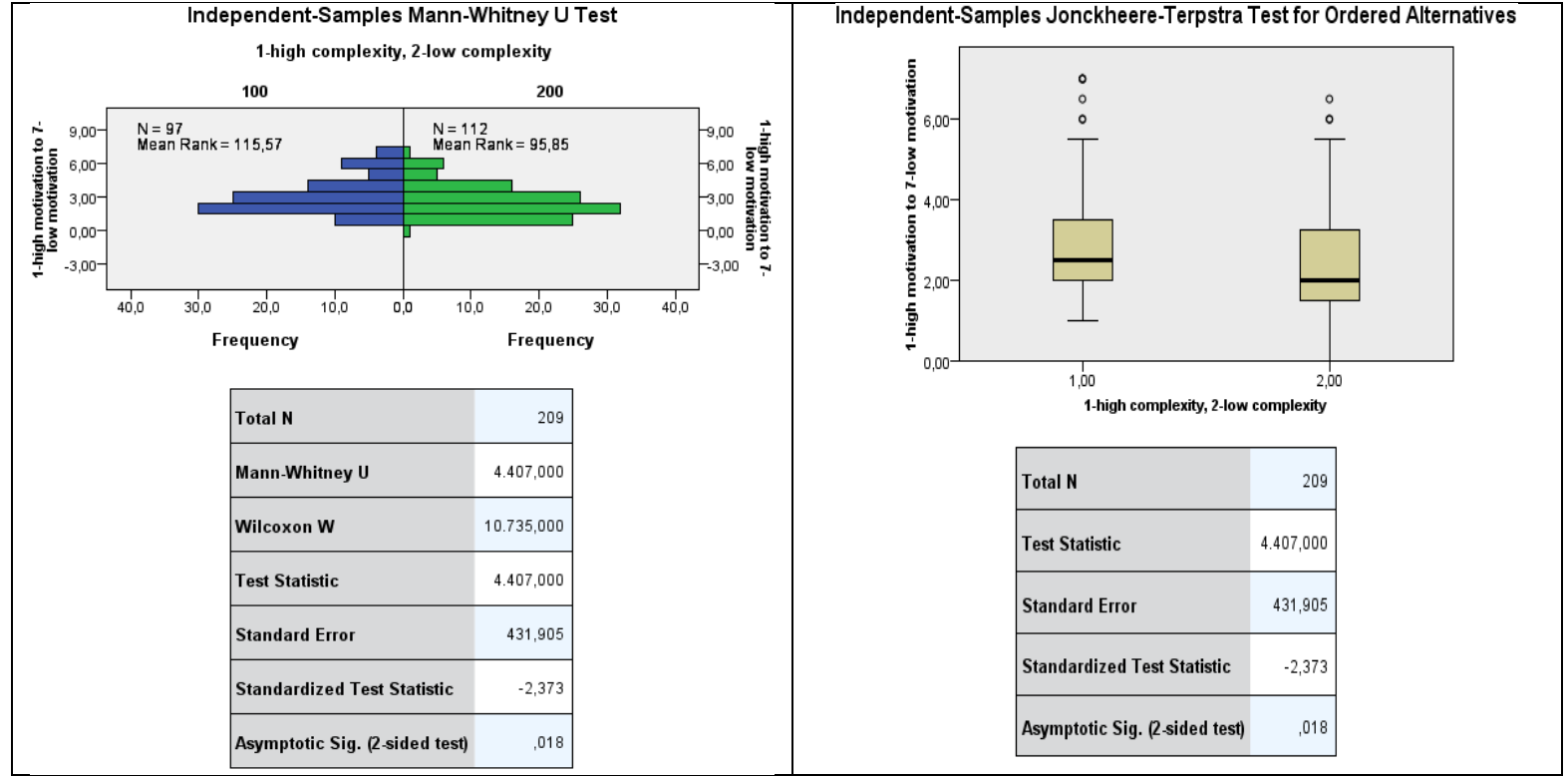

Fig. 3. Mann-Whitney U test and Jonckheere-Terpstra test for Task Complexity

The visualisation of the tests indicates once more that increasing complexity reduces motivation. As already shown in section 4.1, the further tests conducted in this section corroborate the results and provide further evidence regarding this issue. Summarising, the analysis exhibits an essential impact as increasing task complexity moderates the auditor's motivation. Thus, taken these insights together, hypothesis 2 can be supported.

\section{$5 \quad$ Discussion of results}

Within the data analysis, it is shown that risk preference and task complexity affect auditor's motivation. However, no effect could be found regarding the liability situation.

The measured motivation was significantly higher for risk-averse individuals than for risk-neutral and riskloving individuals. Hence, as predicted, higher risk aversion leads to an increased auditor's motivation. It is shown that risk preference has a decisive impact on the motivation which in turn positively affects the judgment performance and the audit procedure (Bonner 2008; Mala and Chand 2015). The findings seem to be consistent with the majority of the literature, which argues that risk-averse individuals are more eager to avoid risks and negative consequences compared with risk-loving individuals (Klein and Scholl 2004; Pummerer et al. 2013; Amir et al. 2014). In line with prior literature increasing task complexity lowers motivation (Chan 2005; Chan and Song 2010). Although complexity may influence motivation in different ways (Atkinson 1957), the results indicate that 
in an audit context the incentive effect of avoiding failure (a negative form of motivational incentive) might be the main driver for the auditor's motivation.

As usual in experimental research, the present study is confronted with some caveats. Therefore, the control variables age, sex, duration as well as various control questions regarding the audit procedure were included to control for potential threats to the external and internal validity of the experiment (e.g. Wik et al. 2004; Smith 2011). The present study uses a combined situation/domain specific measure for the measurement of risk preference since no superior measure for risk preference exists. Using a different measurement may lead to different results (Weber et al. 2002; Reynaud and Couture 2012). This problem also exists concerning the measurement of motivation.

\section{Conclusion}

The present study analyses factors that affect the auditor's motivation. More specifically the impact of risk preference and task complexity is examined in this context. A $2 \times 2$ mixed-subjects case-based experiment was conducted to carry out the research project.

The result of the data analysis shows decisive effects of risk preference on the auditor's motivation and a significantly higher motivation of risk-averse individuals compared with risk-neutral and risk-loving participants. These findings can be explained by the preferences of the respective risk groups; higher risk-aversion is generally accompanied by greater caution and higher sensitivity to risk. Risk-averse individuals are more eager to avoid negative consequences (e.g.monetary losses, reputation damage) and are therefore more motivated than individuals classified as risk-neutral or risk-loving. Following the stream of literature, which shows and discusses the positive effects of motivation on the audit process, one could assume that increasing risk aversion leads to more precise judgments as well as to an improvement of the audit process.

According to the results, increasing task complexity causes significantly lower motivation. Thus, also task complexity has a vital impact in this context. Various theories offer insights into the main drivers of motivation and try to explain what causes the inner force that stimulates actions or certain behaviour of individuals. The achievement of success and the avoidance of loss are prominent in the literature regarding this issue. In the audit context it could be argued that the avoidance of loss may have a stronger impact on motivation since the only failure causes significant damage to the auditor. On the other hand, it is more or less presumed that the audit is carried out successfully. That means that in audit procedures the absence of failure generally represents success. Several studies arguing a negative effect of task complexity on motivation as the achievement of goals become more difficult (e.g. the avoidance of failure). Although literature discusses that increasing complexity might also have a positive effect on motivation in case of achieving success (due to the higher pride to accomplish the task), in an audit context, however, the avoidance of potential losses might be dominating as discussed above.

This study offers insights into the audit process and several interaction effects of audit-specific factors on judgment and decision-making. Especially the dependencies and the role of the auditor's motivation within the critical steps of an audit process are investigated and discussed. It closes the identified gap of the examination of the influence of motivation on the judgment and decision making and adds further insights to the impact and interaction of person-specific, task-specific and environmental-specific factors to previous literature dealing with judgment and decision-making and audit quality.

The research has raised many questions in need of further investigation. More research is required to investigate the effects of additional person-specific factors on motivation like expertise or self-efficacy of an individual. Conducting the suggested research would help to establish a higher degree of accuracy and a deeper understanding throughout the audit process.

\section{References}

Van der Geer, J., Hanraads, J. A. J., \& Lupton, R. A. (2000). The art of writing a scientific article. Journal of Science Communication, 163, 51-59.

Strunk, W., Jr., \& White, E. B. (1979). The elements of style (3rd ed.). New York: MacMillan.

Mettam, G. R., \& Adams, L. B. (1999). How to prepare an electronic version of your article. In B. S. Jones \& R. Z. Smith (Eds.), Introduction to the electronic age (pp. 281-304). New York: E-Publishing Inc.

Fachinger, J., den Exter, M., Grambow, B., Holgerson, S., Landesmann, C., Titov, M., et al. (2004). Behavior of spent HTR fuel elements in aquatic phases of repository host rock formations, 2nd International Topical Meeting on High Temperature Reactor Technology. Beijing, China, paper \#B08.

Fachinger, J. (2006). Behavior of HTR fuel elements in aquatic phases of repository host rock formations. Nuclear Engineering \& Design, 236, 54.

Amabile, T. M. (1988). A model of creativity and innovation in organizations. Research in Organizational Behavior, 10, 123-167.

Amir, E., Kallunki, J.-P., \& Nilsson, H. (2014). The association between individual audit partners' risk preferences and the composition of their client portfolios. Review of Accounting Studies, 19/1, 103-133. 
Ashton, R. \& Kramer, S. (1980). Students as Surrogates in Behavioural Accounting Research. Journal of Accounting Research, 1-15.

Atkinson, J. W. (1957). Motivational determinants of risk-taking behavior. Psychological Review, 64/6(1), 359372.

Bigus, J. (2007). Die Sorgfaltsanreize des Wirtschaftsprüfers bei beschränkter Haftung. Zeitschrift für betriebswirtschaftliche Forschung, Vol. 59 No.1, pp. 61-86.

Bigus, J. (2011). Auditors' liability with overcompensation and reputation losses. OR Spectrum, 33/2, $287-307$.

Bonner, S. (1994). A model of the effects of audit task complexity. Accounting, Organizations and Society, 19, $213-234$

Bonner, S. (2008). Judgment and Decision Making in Accounting. Upper Saddle River: Pearson/Prentice Hall;; N.J.

Bonner, S. \& Sprinkle, G. (2002). The effects of monetary incentives on effort and task performance - theories, evidence, and a framework for research. Accounting, Organizations and Society, 27/4-5, 303-345.

Bowrin, A. R. \& King, J. (2010). Time pressure, task complexity, and audit effectiveness. Managerial Auditing Journal, 25 (2), 160-181.

Campbell, D. (1988). Task Complexity - A Review and Analysis. Academy of Management Review, 13, 40-52.

Carver, C. S. \& Scheier, M. F. (1998). On the self-regulation of behavior. New York: Cambridge University Press.

Chan, S. H. (2005). A motivational framework for understanding IS use and decision performance. Review of Business Information Systems, 9/4, 101-117.

Chan, S. H., Qian S. \& Lee J. Y. (2014). The Impact of Task Complexity, Task Motivation, Decision Support System (DSS) Motivation, and DSS Use on Performance. PACIS (2014).

Chan, S. \& Song, Q. (2010). Motivational Framework: Insights into Decision Support System Use and Decision Performance. In: M. Cioca \& L.-I. Cioca (Eds.), Decision Support Systems used in Disaster Management. INTECH Open Access Publisher.

Chan, S., Song, Q. \& Yao, L. (2014). The Impact of Task Complexity, Task Motivation, Decision Support System (DSS) Motivation, and DSS Use on Judgment Performance. PACIS 2014 Proceedings, 292.

Chung, J. \& Monroe, G. (2001). A research note on the effects of gender and task complexity on an audit judgment. Behavioral Research in Accounting, 1, 111-125.

DeFond, M. L. \& Zhang, J. (2014). A review of archival auditing research. Journal of Accounting \& Economics, $58 / 2 / 3,275-326$.

DeZoort, T., Harrison, P. \& Taylor, M. (2006). Accountability and auditors' materiality judgments: The effects of differential pressure strength on conservatism, variability, and effort. Accounting, Organizations and Society, 31/4, 373-390.

Dusenbury, R., Reimers, J. \& Wheeler, S. (2000). The audit risk model: An empirical test for conditional dependencies among assessed component risks. Auditing: A Journal of Practice and Theory, 19(2),105-117.

Dye, R. (1995). Incorporation and the audit market. Journal of Accounting \& Economics 19, 75-114.

Eccles, J. S. P. \& Wigfield, A. (1995). In the Mind of the Actor. Personality and Social Psychology Bulletin, 21(3), 215-225.

Eccles, J.S.P. \& Wigfield, A. (2002). Motivational Beliefs, Values, and Goals. Annual Review of Psychology, 53(1), 109-132.

Eccles, J. S. P., Adler, T., Futterman, R., Goff, S., Kaczala, C., Meece, J. \& Midgley, C. (1983). Expectancies, values, and academic behaviors. In: J. Spence (Eds.), Achievement and Achievement Motives, New York: W. H. Freeman and Co., 75-146.

Eysenck, M. (1986). A Handbook of Cognitive Psychology, London: Erlbaum.

Farmer, T. A. (1993). Testing the Effect of Risk Attitude on Auditor Judgment Using Multiattribute Utility Theory. Journal of Accounting, Auditing \& Finance, 8(1), 91-110.

Fatemi, D. J. (2012). An Experimental Investigation of the Influence of Audit Fee Structure and Auditor Selection Rights on Auditor Independence and Client Investment Decisions. Auditing a Journal of Practice and Theory, 31(3), 75-94.

Fisher, C.W., Chengalur-Smith, I. \& Ballou, D.P. (2003). The impact of experience and time on the use of data quality information in decision making. Information Systems Research, 14(2), 170-188.

Funke, J. (1991). Solving complex problems: Exploration and control of complex systems. In: R. J. Sternberg \& P. A. Frensch (Eds.), Complex problem solving: Principles and mechanisms (pp. 185-222). Hillsdale: Erlbaum, 185-222.

Gill, T. G. \& Hicks, R. C. (2006). Task Complexity and Informing Science: A Synthesis. Informing Science, 130 .

Gronewold, U. (2006). Die Beweiskraft von Beweisen: Audit Evidence bei betriebswirtschaftlichen Prüfungen. Düsseldorf: IDW Verlag.

Hackman, J. R. \& Oldham, G. R. (1980). Work redesign reading. MA: Addison-Wesley. 
Hadrdies, K., Breesch, D. \& Branson, J. (2013). Gender differences in overconfidence and risk taking: Do selfselection and socialization matter?. Economic Letters, 118(3), 442-444.

Hidi, S. \& Harackiewicz, J.M. (2001). Motivating the academically unmotivated: A critical issue for the $21 \mathrm{st}$ century. Review of Educational Research, 70, 151-180.

Hollander, M. \& Wolfe, D. (1999). Nonparametric statistical methods, Wiley-Interscience.

Holt, C. \& Laury, S. (2002). Risk Aversion and Incentives Effects. American Economic Review 92, 1644-1655.

Humphrey, M. \& Revelle, W. (1984). Personality, Motivation, and Performance - A Theory of the Relationship between Individual Differences and Information Processing. Psychological Review, 153-184.

Jacko, J.A. \& Salvendi, G. (1996). Hierarchical menu design: Breadth, depth and task complexity. Perceptual and Motor Skills, 82, 1187-1201.

Johnstone, K. M. (2000). Client-Acceptance Decisions: Simultaneous Effects of Client Business Risk, Audit Risk, Auditor Business Risk, and Risk Adaptation. Auditing: A Journal of Practice \& Theory, 19(1), 1-25.

Kahneman, D. (1973). Attention and effort. Englewood Cliffs: Prentice Hall.

Kanfer, R. (1990). Motivation Theory and Industrial and Organizational Psychology. In: M. Dunnette, \& L. Hough (Eds.), Handbook of industrial and organizational psychology (pp. 57 - 170), Paolo Alto: Consulting Psychology Press.

Klein, R. \& Scholl, A. (2004). Planung und Entscheidung: Konzepte, Modelle und Methoden einer modernen betriebswirtschaftlichen Entscheidungsanalyse. München: Vahlen.

Klemz, B.R. \& Gruca, T.S. (2003). Dueling or the battle royale? The impact of task complexity on the evaluation of entry threat. Psychology \& Marketing, 20(11), 999-1016.

Klersey, G.F. \& Roberts, M.L (2010). Audit partners' individual risk preferences in client retention decisions. Academy of Accounting and Financial Studies Journal, 14(2), 115-129.

Laux, H., Gillenkirch, R. \& Schenk-Mathes, M. (2014). Entscheidungstheorie. Berlin: Springer.

Lawler, E. (1994). Motivation in Work Organizations. San Francisco: Jossey-Bass.

Lehtinen, A. \& Kvist, L. (2018). Gender, Independence and Risk Preference: A quantitative study of listed Swedish companies. Umea University: Independent Thesis.

Mala, R. \& Chand, P. (2015). Judgment and Decision-Making Research in Auditing and Accounting: Future Research Implications of Person, Task, and Environment Perspective. Accounting Perspectives, 14, 1-50.

McClelland, D. (1961). The achieving society. Princeton: Van Nostrand Company Inc.

Miller, C., Fedor, D. \& Ramsay, R. (2006). Effects of Discussion of Audit Reviews on Au-ditors' Motivation and Performance. Behavioral Research in Accounting, 18, 135-146.

Mohd Iskandar, T., Nelly Sari, R., Mohd-Sanusi, Z. \& Anugerah, R. (2012). Enhancing audi-tors' performance. Managerial Auditing Journal, 27(5), 462-476.

Mohd-Sanusi, Z. \& Mohd-Iskandar, T. (2007). Audit judgment performance: Assessing the effect of performance incentives, effort and task complexity. Managerial Auditing Journal, 22, 34-52.

Mohd-Sanusi, Z., Mohd-Iskandar, T. \& Poon, J. (2007). Effects of goal orientation and task complexity on audit judgment performance. Malaysian Accounting Review, 6, 123-139.

Nelson, M. \& Tan, H. (2005). Judgment and Decision Making Research in Auditing: A Task, Person, and Interpersonal Interaction Perspective. AUDITING: A Journal of Practice \& Theory, Supplement 2005, 24, 4171.

O'Donnell, E. \& Johnson, E. N. (2001). The Effects of Auditor Gender and Task Complexity on Information Processing Efficiency. International Journal of Auditing, 5(2), 91-105.

Pablo, A, Sitkin, S. \& Jemison, D. (1996). Acquisition Decision-Making Processes: The Central Role of Risk. Journal of Management, 22, 723-746.

Pintrich, P. R. \& de Groot, E. V. (1990). Motivational and self-regulated learning components of classroom academic performance. Journal of Educational Psychology, 82(1), 33-40.

Pintrich, P. R. \& Schrauben, B., (1992). Student perceptions in the classroom. In: D.H. Schunk, \& J. L. Meece (Eds.), Student perceptions in the classroom (pp. 149-183). Hillsdale: Lawrence Erlbaum Associates.

Prawitt, D. (1995). Staffing Assignments for Judgment-Oriented Audit Tasks: The Effects of Structured Audit Technology and Environment. The Accounting Review, 443-465.

Pummerer, E., Steller, M. \& Baldauf, J. (2013). Prüfungsqualität, Prüferhaftung und Risiko-aversion: Eine analytische Betrachtung der Bedeutung der Risikoaversion für die Prüfungsqualität. Zeitschrift für betriebswirtschaftliche Forschung, 1, 32-59.

Quick, R. (2005). Unabhängigkeit des Abschlussprüfers im Spiegel der Wissenschaft. In: A. Haller (Eds.). Wirtschaftsprüfung und Corporate Governance in Österreich (pp. 91-143), Wien: Linde.

Reynaud, A. \& Couture, S. (2012). Stability of risk preference measure: results from a field experiment on French farmers. Theory and Decision, Vol. 73 No. 2, pp. 203-221.

Rheinberg, F. (2010). Intrinsische Motivation und Flow-Erleben. In: J. Heckhausen \& H. Heckhausen (Eds.), Motivation und Handeln (pp. 365-387), Heidelberg: Springer-Verlag. 
Ryan, R. M. \& Deci, E. L. (2000). When rewards compete with nature - The undermining of intrinsic motivation and self-regulation. In: C. Sansone \& J. M. Harackiewicz (Eds.), Intrinsic and Extrinsic Motivation: The Search for Optimal Motivation and Performance (pp. 257-307), San Diego: Academic Press.

Ryan, R. M., Koestner, R. \& Deci, E. L. (1991). Ego-involved persistence - When free-choice behavior is not intrinsically motivated. Motivation and Emotion, 15, 185-205.

Schiefele, U. (1999). Interest and learning from text. Scientific studies of reading, 3(3), 257-279.

Schwind, J. (2011). Die Informationsverarbeitung von Wirtschaftsprüfern bei der Prüfung geschätzter Werte: Eine verhaltenswissenschaftliche und empirische Analyse, Wiesbaden: Gabler Verlag.

Simunic, D. \& Stein, M. (1996). Impact of litigation risk on audit pricing: A review of the economics and the evidence. Auditing: A Journal of Practice and Theory, 15, 119-134.

Sitkin, S. B. \& Weingart, L. R. (1992). Determinants of Risky Decision-Making Behavior: A Test of the Mediating Role of Risk Perceptions and Prospensity. Academy of Management Journal, 38(69, 1573-1592.

Stone, D. N. \& Kadous, K. (1997). The joint effects of task-related negative affect and task difficulty in multiattribute choice. Organizational Behavior and Human Decision Processes, 70(2), 159-174.

Tan, H.-T. \& Kao, A. (1999). Accountability Effects on Auditors' Performance - The Influence of Knowledge, Problem-Solving Ability, and Task Complexity. Journal of Accounting Research, 37(19), 209-223.

Thomas, K. W. \& Velthouse, B. A. (1990). Cognitive elements of empowerment - An interpretive model of intrinsic task motivation. Academy of Management Review, 15(4), 666-681.

Touré-Tillery, M. \& Fishbach, A. (2014). How to measure Motivation: A Guide for the Experimental Social Psychologist. Social and Personality Psychology Compass, 8(7), 328-341.

Utman, C. H. (1997). Performance effects of motivational state - A meta-analysis. Personality and Social Psychology Review, 1, 170-182.

Wagenhofer, A. \& Ewert, R. (2007). Externe Unternehmensrechnung. Berlin/Heidelberg/New York: Springer.

Weber, E., Blais, A. \& Betz, N. (2002). A Domain-specific Risk-attitude Scale, in Journal of Behavioral Decision Making, 15, 263-290.

Wigfield, A. \& Eccles, J. S. P. (1992). The development of achievement task values - a theoretical analysis. Developmental Review, 12, 265-310.

Zuber, M. \& Guthier, M. (2003). Verfahren zur Erhebung der Risikoeinstellung in der Kapitalanlageberatung. Jahrbuch der Absatz- und Verbrauchsforschung, 49/4. 